\title{
Nitrogen excretion and oxygen consumption on hyper intensive tilapia Oreochromis niloticus culture using three different commercial diets
}

\author{
Samuel López-Tejeida ${ }^{1}$, Juan Fernando García-Trejo ${ }^{1}$, Leticia Félix-Cuencas ${ }^{1}$ \\ Jesús Josafat De León-Ramírez ${ }^{1}$, Maribel Villegas-Villegas ${ }^{1}$ \& Laura Berenice Flores-Tejeida ${ }^{1}$ \\ ${ }^{1}$ División de Estudios de Posgrado, Facultad de Ingeniería \\ Universidad Autónoma de Querétaro, Querétaro, México \\ Corresponding author: Juan Fernando García-Trejo (fernando.garcia@uaq.mx)
}

\begin{abstract}
The fish feed used in aquaculture systems has many nutritional factors like protein, fat, fiber, ash, and humidity; from these factors, one of great importance is protein. The protein of fish feed is obtained from fish meal, and the demand for fish meal has increased; this induces to increase the price. Many pieces of research have been done about this topic to mitigate this problem. This research shows the differences between three commercial foods of the different processes with the same quantity of protein, using tilapia Oreochromis niloticus, to prove any difference between $\mathrm{NO}_{2}{ }^{-}, \mathrm{NO}_{3}^{-}$, and $\mathrm{NH}_{4+}$. Nitrogen compounds were determined with $\mathrm{HACH}$ methods for the DR6000 spectrophotometer. Biometric data were registered throughout the growth of fish, along with measure aerobic metabolism. Results have shown that has better outcomes related to low excretion of nitrogen compound was medium-cost fish feed (MCFF). It also has sound effects associated with the length-weight relationship; that could be connected to these fish feed's protein sources.
\end{abstract}

Keywords: Oreochromis niloticus; nitrogen excretion; oxygen consumption; hyper intensive; aquaculture

\section{INTRODUCTION}

Aquaculture is the animal production industry with the highest growth rate in the last 20 years (Dantas et al., 2017 ); in 2016, the production was 80 million tons (FAO, 2018). The aquaculture is also widely considered an option to fight hunger and poverty in developing countries (Lithgow et al., 2017). One of the most important activities in aquaculture is fish nutrition. Hence $40 \%$ of the total production costs are inverted in fish feed; besides, if this task has inefficiencies will be a loss, especially for intensive aquaculture systems (Zhou et al., 2017). Fish meal is a high quality, very digestible feed ingredient that is preferred to use on the fish diet; it carries large quantities of energy per unit weight. It is an excellent source of protein, lipids (oils), minerals, and vitamins (Hyacinth et al., 2019). Meanwhile, fish feed is made of some sub-products with restricted use because it contains antinutrients; these compounds affect protein and mineralization; another disadvantage is that it de- creases palatability, digestibility, or metabolism. It may even exert a toxic effect resulting in liver damage (Duodu et al., 2018).

The ingredients used in fish feed are small fishes, chopped scrap fish, meat scraps, grain, plant meals, and fish meal. Another important characteristic to consider is that depending on the kind of fish will be the nutritional requirements (Boyd, 2013). However, the main ingredient of aquaculture feeds is fish meal. This ingredient's principal characteristic is digestibility and high protein (Kokou \& Fountoulaki, 2018). Generally, proteins are used for hormone synthesis, cellular homeostasis, and activity to synthesize new tissue or simply grow (Vilhelm et al., 2017).

The diet adds protein, and all the ingredients cannot be assimilated by the fishes and are throw away to the ambient in the form of waste (Valenti et al., 2018). The primary compound found in protein is nitrogen. When the fish uptake this nitrogen-containing compound, the fish metabolize them and are excreted in ammonium $\left(\mathrm{NH}_{4}{ }^{+}\right)$, the principal nitrogenous waste in the water.

Corresponding editor: Mauricio Laterça 
The nitrogen ingests also discharged as waste within 24 $\mathrm{h}$ (Ip \& Chew, 2018). The ammonia can be found in two forms, (un-ionized form) and molecular $\mathrm{NH}_{3}$ form, sometimes called non-dissociated, and the other form is the ammonium (ionic form) $\mathrm{NH}_{4}{ }^{+}$ion. The two forms mentioned before coexisting in the water, and the proportion depends on $\mathrm{pH}$ and water temperature (Svobodova et al., 2017).

There are two other nitrogen compounds, which are nitrite $\left(\mathrm{NO}_{2}^{-}\right)$and nitrate $\left(\mathrm{NO}_{3}^{-}\right)$; nitrite principally comes from the oxidation metabolism of ammonia and gets accumulated because of the imbalance of nitrifying bacterial activity (Yun et al., 2019). High concentrations of nitrite can cause nitrite accumulation in blood plasma (Thi et al., 2019). Also, the nitrite can interfere with the physiological function like oxygen capacity of cell hemoglobin, immune system health, physiological metabolism, and endocrine regulation (Xie et al., 2019). Fishes have various mechanisms to detoxify nitrites, such as methemoglobin reductase secretion or nitrite to nitrate oxidation as this compound is less toxic (Kim et al., 2019). Nitrate is often considered nontoxic in comparison with ammonia and nitrite.

Moreover, nitrate is the most abundant form of inorganic nitrogen in freshwater (Isaza et al., 2018). The high concentration of nitrate causes methemoglobinemia that reduces the capacity of hemoglobin to bind oxygen and carry it through the body (Freitag et al., 2015); other adverse effects are decreased like reproductive maturation, abnormal skin coloration, and tissue damage (Yang et al., 2019). Lastly, nitrogen is essential for animal nutrition and to control environmental pollution. To achieve waste reduction is vital to understand the quantitative nitrogen budget (David \& Proença, 2017).

This study aimed to compare three commercial fish feed with the same quantity protein, using tilapia Oreochromis niloticus, to prove any difference between $\mathrm{NO}_{2}{ }^{-}, \mathrm{NO}_{3}{ }^{-}$, and $\mathrm{NH}_{4}{ }^{+}$. Also, the metabolic rate was measured to relate the consumption of dissolved oxygen between the fish feed. Additionally, to determine the growth and health of organisms, lengthweight relationship and growth between treatments are shown. Lastly, the fish feed had the difference relating to the price; for that reason, the fish feed was differentiated for the price: low-cost fish feed (LCFF), medium cost fish feed (MCFF), and high-cost fish feed (HCFF).

\section{MATERIALS AND METHODS}

\section{Rack system}

Three treatments were realized considering three commercial fish feed, corresponding to LCFF, $\mathrm{MCFF}$ and HCFF, in a rack system to Oreochromis niloticus (Fig. 1).

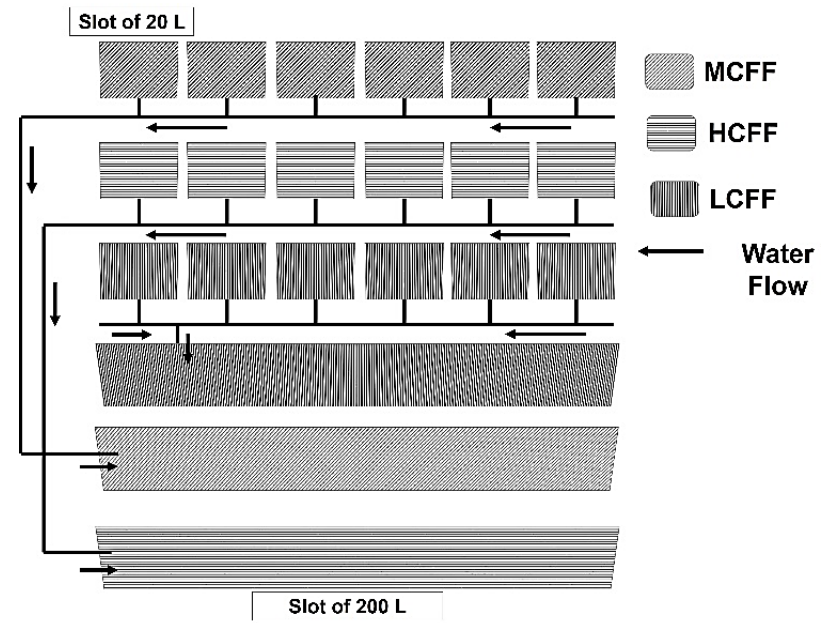

Figure 1. Placement of the three treatments and triplicates in the rack system to compare three commercial fish feed in Oreochromis niloticus. LCFF: low-cost fish feed, MCFF: medium cost fish feed, HCFF: high-cost fish feed.

A device was designed to culture fish with a structure made with 1" stainless steel rectangular tube. The system had 24 fishbowls, each of $20 \mathrm{~L}$, made of acrylic glass $(30 \mathrm{~cm}$ long $\times 25 \mathrm{~cm}$ wide $\times 20 \mathrm{~cm}$ high). Besides, the system had three rows of six fishbowls, each row had a tank also made of acrylic glass with a capacity of $80 \mathrm{~L}(150 \mathrm{~cm}$ long $\times 32 \mathrm{~cm}$ wide $\times 30 \mathrm{~cm}$ high), which works like water reservoir and avoid that the concentrations of nitrogen compounds get dangerous values for fishes. A Topaz Airsep oxygen generator was used to oxygenate the water in all tanks; this generator can produce an oxygen flow of $0.31 \mathrm{Nm}^{3}$ $\mathrm{h}^{-1}$, at $62 \mathrm{KPa}(9 \mathrm{psi})$ with a purity of $93 \%$.

\section{Experimental design}

The experiment had three treatments and six replicates with an experimental unit of six fish, under a culture density of 270 ind $\mathrm{m}^{-3}$. An amount of 108 individuals were randomly selected and cultured in the system for one week to get adapted. After adaptation week, biometry was done using a digital Mitutoyo ${ }^{\circledR}$ Vernier to get the length and a digital Sartorius ${ }^{\circledR}$ AY303 scale to gain weight. This first biometry was considered as an initial fish condition. During all experiments, the fish feed was supplied four times per day, with $10 \%$ of their total biomass. Treatments were ordered by fish feed; treatment 1 was MCFF, treatment 2 was HCFF, and treatment 3 was LCFF. Table 1 shows the nutritional aspects of each treatment.

\section{Respirometry and metabolic rate measurements}

After two weeks that fishes stayed in the rack system and were fed with the different fish feed, a respirometry was done to measure the differences between metabolisms due to the fish feed. The metabolism of freshwater fish may vary depending on the physical and 
Table 1. Percent of nutritional aspects of fish feed used. LCFF: low-cost fish feed, MCFF: medium cost fish feed, HCFF: high-cost fish feed.

\begin{tabular}{lccccc}
\hline Fish feed & $\begin{array}{c}\text { Protein } \\
(\%)\end{array}$ & $\begin{array}{c}\text { Fat } \\
(\%)\end{array}$ & $\begin{array}{c}\text { Fiber } \\
(\%)\end{array}$ & $\begin{array}{c}\text { Ash } \\
(\%)\end{array}$ & $\begin{array}{c}\text { Humidity } \\
(\%)\end{array}$ \\
\hline LCFF & 45 & 16 & 2.5 & 12 & 12 \\
MCFF & 45 & 16 & 2.5 & 12 & 11 \\
HCFF & 44 & 15 & 2.5 & 12 & 12 \\
\hline
\end{tabular}

chemical variables of the water. In $\mathrm{pH}$, the optimal range is 6.5-9.0. This range may vary depending on the carbonated compounds present in water (Mohammadi et al., 2019). Optimal temperature ranges may vary depending on the species that are being cultivated, but this can be $24-30^{\circ} \mathrm{C}(\mathrm{Li}, 2017)$. Dissolved oxygen (DO) is considered on $6 \mathrm{mg} \mathrm{L}^{-1}$ (Ma et al., 2019). AbdelTawwab et al. (2019) and Wang et al. (2019) mentioned the rate of oxygen consumption could be used as a primary parameter to evaluate metabolic activities. The oxygen consumption can be used to measure the respiration rate of fish; for this reason, the respiration rate is used according to a measure for the metabolic rate (Magnhagen et al., 2018). For this research, a stop-flow respirometry was made, were used 17 plastic containers of $10 \mathrm{~L}$ as a chamber, five chambers were used for each treatment, and the remaining two were used as a control.

Five individuals from each treatment were randomly selected to measure aerobic metabolism (oxygen consumption $=\mathrm{QO}_{2}$ ), using a closed respirometric chamber technique with constant temperature and a known water volume (Timmons et al., 2002; SotoZarazúa et al., 2010). Measurements of dissolved oxygen and ammonium were taken every four hours (14:00, 18:00, 22:00, 02:00, 06:00, and 10:00 h) during a $24 \mathrm{~h}$ cycle. The fish feed was added to each chamber per treatment, considering the $10 \%$ of fish biomass, and a water sample was taken. All the fish used to determine $\mathrm{QO}_{2}$ were euthanized on ice immediately after finishing the experiment to determine its dry weight and get the relation of the oxygen consumed by biomass (Steffensen, 1989).

During the experiment, nitrogen compounds were also measures like $\mathrm{NO}_{2}{ }^{-}, \mathrm{NO}_{3}{ }^{-}$and $\mathrm{NH}_{4}{ }^{+}$in wastewater. A total water change was made in each treatment one day before starting the experiment. The next day fish feed was given at 8:00, 12:00 and 16:00 $\mathrm{h}$; the samples were taken at 9:00, 13:00, 17:00, 21:00, 1:00 and 9:00 $\mathrm{h}$, avoiding to take bubble airs fish feed or excretions in the sample.

\section{Fish metabolism behavior in seven days}

An important fact in the aquaculture is the feeding. Vilhelm et al. (2017) mention that meanwhile, the largest ration size led to a high content of lipids and reduced the protein retention efficiency (PER); also, the increase of fat deposition involves the destination of ingested protein $\mathrm{N}$ and can be fecal excretion or branchial excretion. Considering the results from $24 \mathrm{~h}$ behavior, the next part of this research was to obtain the $\mathrm{NO}_{2}{ }^{-}, \mathrm{NO}_{3}{ }^{-}$and $\mathrm{NH}_{4}{ }^{+}$behavior in fish water of each fish feed during one week. The experiment began after 24 $h$. The fishes were fed three times per day (08:00, 12:00 and 16:00 h), and samples were taken after one hour of the first feeding for analysis.

\section{Fish metabolism in seven days with $10 \%$ of water replacement}

This part aimed to study the nitrogen compounds present in the water, considering daily $10 \%$ of water changes for seven days. Some research has made a replacement of $15-20 \%$ were the systems had continuous water flow. Hassaan et al. (2018) and Nguyen et al. (2019) mention that one-third of water volume in each tank was replaced daily by aerated freshwater after removing the accumulated excreta. The experiment began with feeding the fish, and after one hour, the sample was taken, and then $10 \%$ of water replacement was done. Uneaten food, feces, and sediments were also removed every day. The samples were taken after one hour of the first feeding for analysis of nitrogen compounds.

\section{Determination of nutrients in the water}

The measurement of nitrogen compounds was made using an analytical method. The importance of water analysis lies in the fact that concentrations must be suitable for the organisms. Also, Groenveld et al. (2019) mention that aquaculture's nitrogen emissions must have more attention because the effects of reactive nitrogen; lead to acidification because of $\mathrm{NH}_{3}{ }^{-}$and eutrophication because of $\mathrm{NH}_{4}{ }^{+}$and $\mathrm{NO}_{3}{ }^{-}$. The levels recommend for the organisms are $\mathrm{NH}_{3}{ }^{-} 0.23 \pm 0.02 \mathrm{mg}$ $\mathrm{L}^{-1}, \mathrm{NO}_{2}^{-} 0.39 \pm 0.22 \mathrm{mg} \mathrm{L}^{-1}, \mathrm{NO}_{3}^{-} 0.89 \pm 0.37 \mathrm{mg} \mathrm{L}^{-1}$ (Estim et al., 2018).

Analysis of the samples was determined using a Hach ${ }^{\circledR}$ DR6000 spectrophotometer; an analysis of $\mathrm{NH}_{4}{ }^{+}$ was done using the $8038 \mathrm{Hach}^{\circledR}$ method called Nessler with an interval of $0.02-250 \mathrm{mg} \mathrm{L}^{-1}$. This method uses a mineral stabilizer, which reduces the sample hardness. A dispersing agent contributes to forming coloration with the Nessler with the ammonium ions; this reaction can be measured at $425 \mathrm{~nm}$. The $\mathrm{NO}_{2}{ }^{-}$ analysis was done with the $8507 \mathrm{Hach}^{\circledR}$ method called diazotization with an interval of $0.02-2.50 \mathrm{mg} \mathrm{L}^{-1}$. The 
sample reacts with the sulfanilic acid to form diatonic salt that reacts with the chromotropic acid to produce a pink color proportional to the quantity of nitrite. It can be measured at $507 \mathrm{~nm}$. The $\mathrm{NO}_{3}^{-}$analysis was determined with the $8039 \mathrm{Hach}^{\circledR}$ method called cadmium reduction with an interval of $0.3-30 \mathrm{mg} \mathrm{L}^{-1}$; in this procedure, the metallic cadmium reduces nitrite to nitrate present in the sample. The nitrite ion reacts in the medium acid with the sulfanilic acid to form an intermediate diazonium salt; this salt reacts with the gentisic acid to form a solution with amber color that can be measured at $500 \mathrm{~nm}$.

\section{Length-weight relationship}

Length-weight relationships are used for estimating the condition factor; this condition helps to know the fatness or well-being of fishes (Rodriguez et al., 2017). An equation $\left(\mathrm{W}=\mathrm{a} \mathrm{L}^{\mathrm{b}}\right)$ is used to estimate the relationship between weight $(\mathrm{g})$ and length $(\mathrm{cm})$, the above mentioned can be transformed to:

$$
\log (W)=\log (a)+b \log (L)
$$

When this formula is applied, $b$ may deviate from the ideal value of 3.0, representing an isometric growth; on the other side, if $b$ is less than 3.0 means that fish is becoming slimmer with increasing length, and growth will be negatively allometric. In the other case, when $b$ is greater than 3.0 indicate that the fish is becoming heavier, showing positive allometric growth and reflecting optimum condition for depending on the kind of fish feed; this is related to the content of protein (Jisr et al., 2018).

\section{Statistical analysis}

Water data analysis were processed using OriginLab ${ }^{\circledR}$ 8 and Statgraphics ${ }^{\circledR}$ Centurion XV. A single factor ANOVA with Tukey HSD was used to test the significance $(P<0.05)$ of differences between treatments based on the mean values of data collected. Graphs were done with the means of using the standard deviations.

\section{RESULTS}

\section{Nitrogen compounds analyzed in fish feed used}

Figure 2 shows $\mathrm{NO}_{2}{ }^{-}$concentration of Oreochromis niloticus in $24 \mathrm{~h}$, seven days without water exchange, and seven days with water $10 \%$ exchange. In $24 \mathrm{~h}$, the high-cost fish feed (HCFF) reached the high concentration, and the medium cost fish feed (MCFF) the lowest, having significant differences. The monitoring during seven days without water exchanges shows an accumulation of nitrites with a toxic amount. That is why partial water exchange is important, as shown in the graph with water exchange, where the behavior begins to stabilize from the fifth day.

Nitrates $\left(\mathrm{NO}_{3}{ }^{-}\right)$did no show significant differences in their behavior during $24 \mathrm{~h}$ for three treatments. The same trend occurred in 7-day monitoring without water exchange; however, significant differences were observed from day five, having a higher concentration in MCFF treatment and a lower concentration in the lowcost fish feed (LCFF) treatment, reaching a maximum amount of $40 \mathrm{mg} \mathrm{L}^{-1}$ of $\mathrm{NO}_{3}^{-}$. The trend in seven days with water exchange had similar behavior in all treatments (Fig. 3).

Ammonium $\left(\mathrm{NH}_{4}{ }^{+}\right)$shows the same trend in $24 \mathrm{~h}$ and seven days monitoring, an ascending behavior, with a greater amount in HCFF but without showing significant differences (Fig. 4). It reached a maximum value of $5 \mathrm{mg} \mathrm{L}^{-1}$ of ammonium in seven days of monitoring, being a toxic amount for fish. The aforementioned is shown in graph with water replacements, where values less than $1 \mathrm{mg} \mathrm{L}^{-1}$ of $\mathrm{NH}_{4}{ }^{+}$were achieved, which are tolerable by organisms.

The HCFF has more quantity of nitrogen compounds in the experiments of $24 \mathrm{~h}$. The high amounts of these nitrogen compounds obtained by the HCFF could be considered as energy expenditure.

\section{Fish metabolic rate}

Metabolism behavior shows the same trend in the three treatments, showing no significant differences, with a maximum consumption peak at night and less consumption during the day. The daily oxygen consumption per treatment is shown (Fig. 5). The metabolic rates are related to oxygen consumption, and this is directly linked to fish size, feeding rate, activity level, system cleanliness from wastes, and water temperature. Tilapia $O$. niloticus could be better adapted to the occasional low DO levels than cold water species, even though all species can tolerate low DO levels. There is a particular relation between oxygen consumption and the excretion of nitrogen compounds, especially the excretion of $\mathrm{NH}_{4}^{+}$, considering the fish weight and time.

The MCFF had less consumption of dissolved oxygen, and excretion of $\mathrm{NH}_{3}{ }^{+}$was less compared with the other two fish feed. The LCFF had low levels related to nitrogen compounds and had low levels of consumed DO, and, in the case of $\mathrm{NH}_{4}{ }^{+}$, it had low levels compared with the other two fish feed.

\section{Length-weight relationship}

The length-weight relationship was obtained for the three treatments in the present study, getting the same regression coefficient in all of them, with a value of 2.9, which suggests an isometric growth, indicating a good 

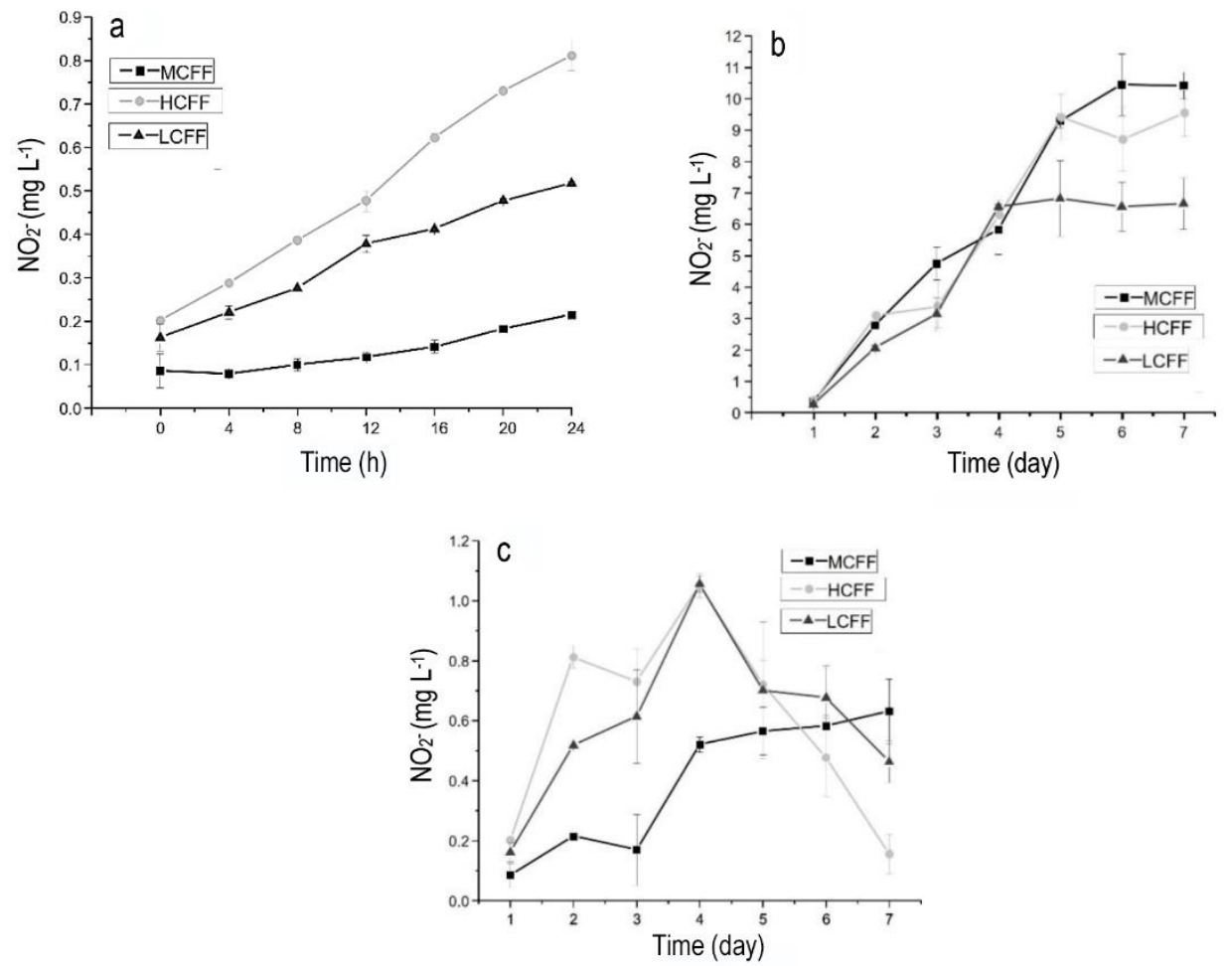

Figure 2. Quantities of $\mathrm{NO}_{2}^{-}$obtained to compare three commercial fish feed Oreochromis niloticus. a) Experiment of 24 $\mathrm{h}, \mathrm{b}$ ) experiment of seven days without water exchange, c) experiment with $10 \%$ water exchange. LCFF: low-cost fish feed, MCFF: medium cost fish feed, HCFF: high-cost fish feed.
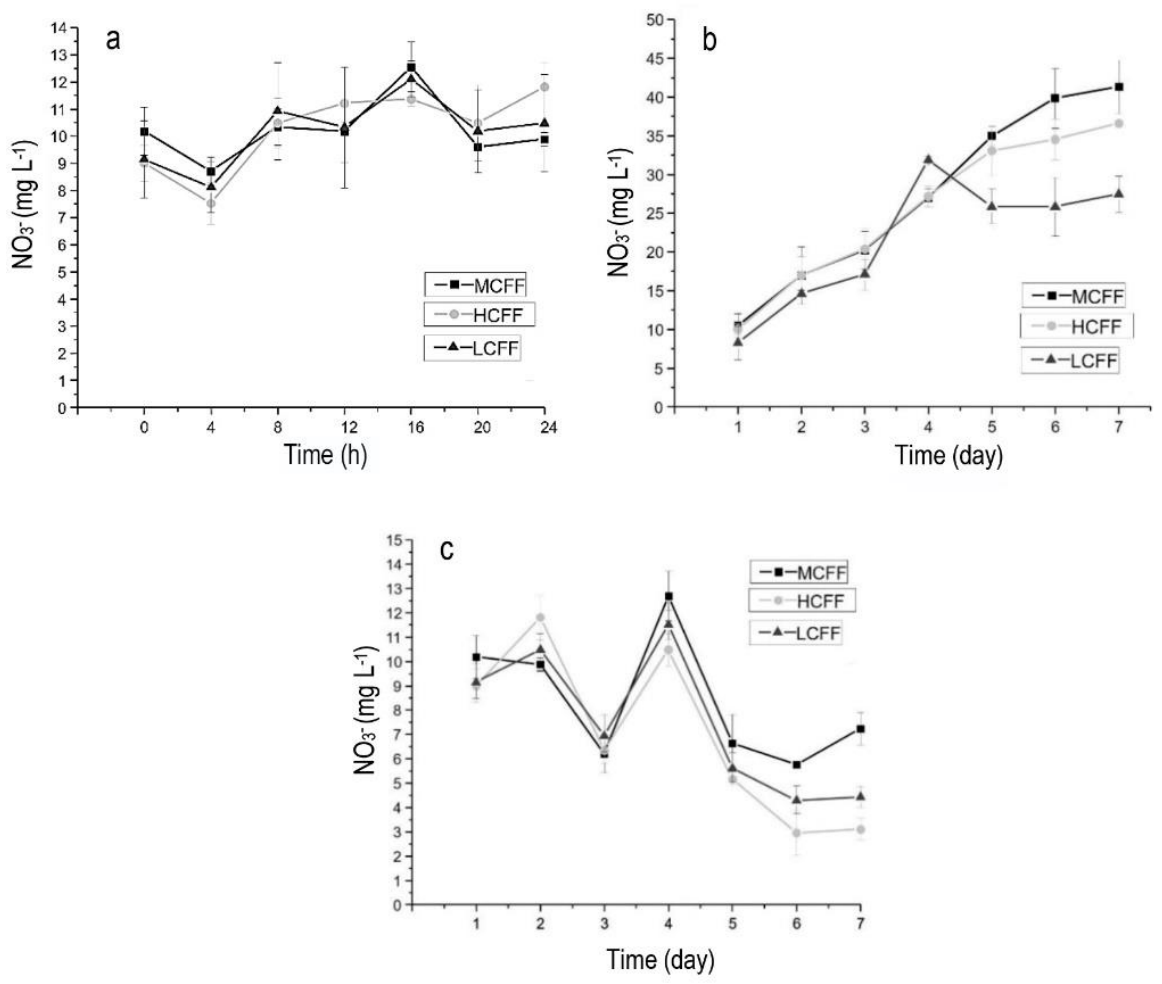

Figure 3. Quantities of $\mathrm{NO}_{3}{ }^{-}$to compare three commercial fish feed Oreochromis niloticus. a) Experiment of $24 \mathrm{~h}$, b) experiment of seven days without water replacement, c) experiment with $10 \%$ water exchange. LCFF: low-cost fish feed, MCFF: medium cost fish feed, HCFF: high-cost fish feed. 

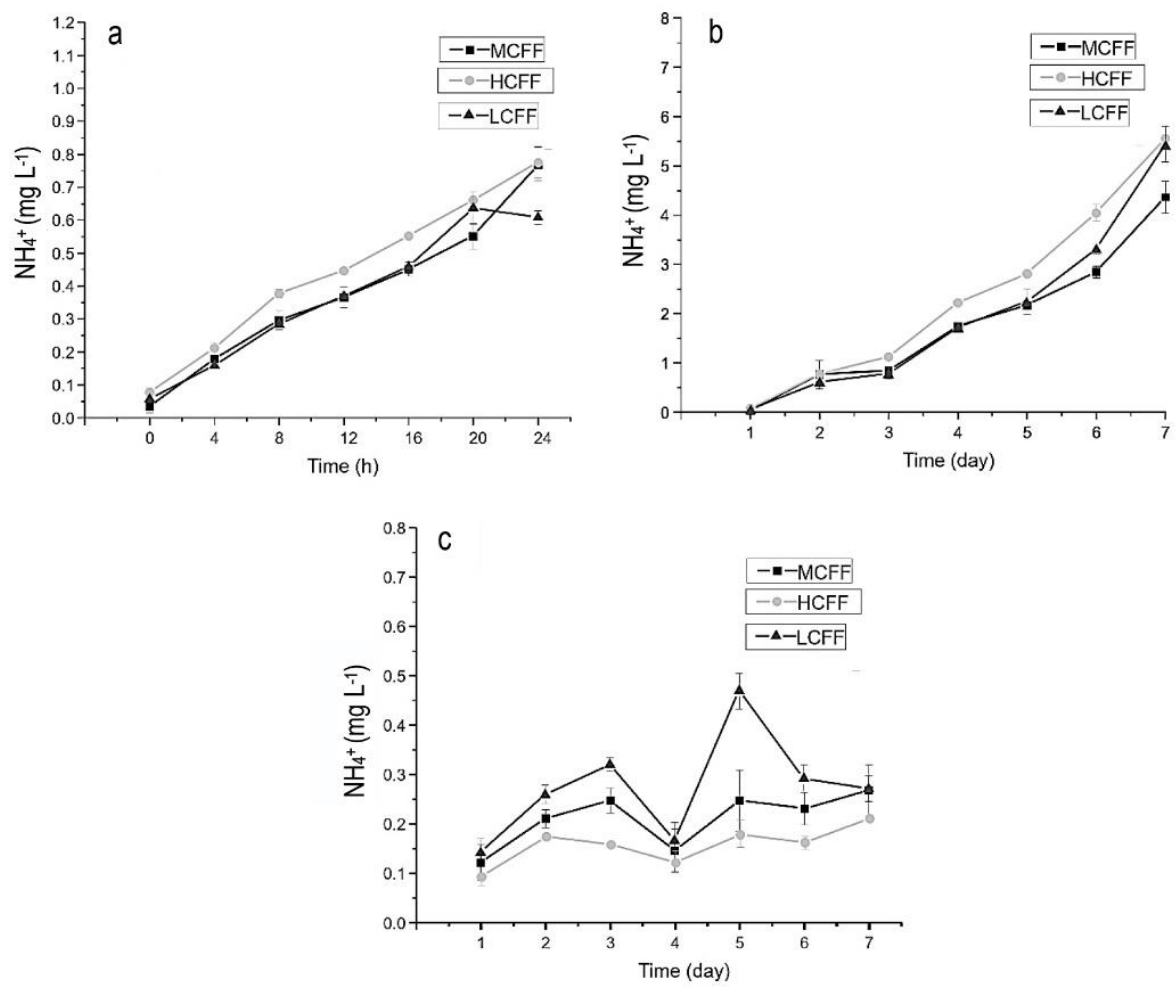

Figure 4. Quantities of $\mathrm{NH}_{4}^{+}$to compare three commercial fish feed Oreochromis niloticus. a) Experiment of $24 \mathrm{~h}$, b) experiment of seven days without water replacement, c) experiment with $10 \%$ water exchange. LCFF: low-cost fish feed, MCFF: medium cost fish feed, HCFF: high-cost fish feed.

physiological state; in Figures 6-8, are shown the relation length-weight obtained in MCFF, HCFF and LCFF respectively.

\section{Fish growth}

In all the aquaculture systems, fish growth is important because it is one of the aquaculture's objectives to improve fish growth. Figure 9 shows growth performance between treatments having significant differences, resulting in a higher growth MCFF treatment, followed by HCFF treatment and the lowest growth LCFF treatment. Protein is the main component of fish muscle and is the source of nitrogen excretion. The ingested protein by fish is digested in the stomach and absorbed in the intestine as amino acids and peptides. These are used for muscle growth, energy production, or both, depending on the fish condition and feed composition. When the protein is metabolized, the final products are inorganic nitrogen, $\mathrm{CO}_{2}$, and water. Subsequently, said inorganic nitrogen would be released as either ammonia $\left(\mathrm{NH}_{3}{ }^{+}\right)$. An important characteristic of the protein is that if the fish entirely digested it, everything would be absorbed by the fish, and the feces would not contain proteins. From those above, and related to fish growth, it was observed that protein in MCFF is the most digestible by organisms.

\section{DISCUSSION}

Previous research has shown that $60 \%$ of fish feed used in aquaculture was in the form of tiny particles. The decomposition of said particles consumes oxygen, produces ammonia, and other toxic substances that affect fish welfare and cause a heavy burden on filtration and oxygenation equipment (Zhou et al., 2018). An element of great importance in biological systems is nitrogen; this is a fundamental component of amino acids, proteins, and nucleic acids. The catabolism of these nitrogen-containing compounds releases ammonia, which is toxic and must be eliminated. When the fish consume the amino acids present in the food, they digest them to obtain proteins. The amount of amino acids that the fish absorbs for growth and development exceeds those it needs; for this reason, it degrades since this excess cannot be stored (Ip \& Chew, 2018). Hence suppose the water is disposed of in the water effluents. In that case, this could be a big problem, can cause issues like eutrophication of aquatic bodies, which damages the flora and fauna that grow in the water and disturbs the food chain and food web of the ecosystem (Singh et al., 2019). Recirculating aquaculture systems (RAS) is used to avoid this kind of problem. In this kind of system, 

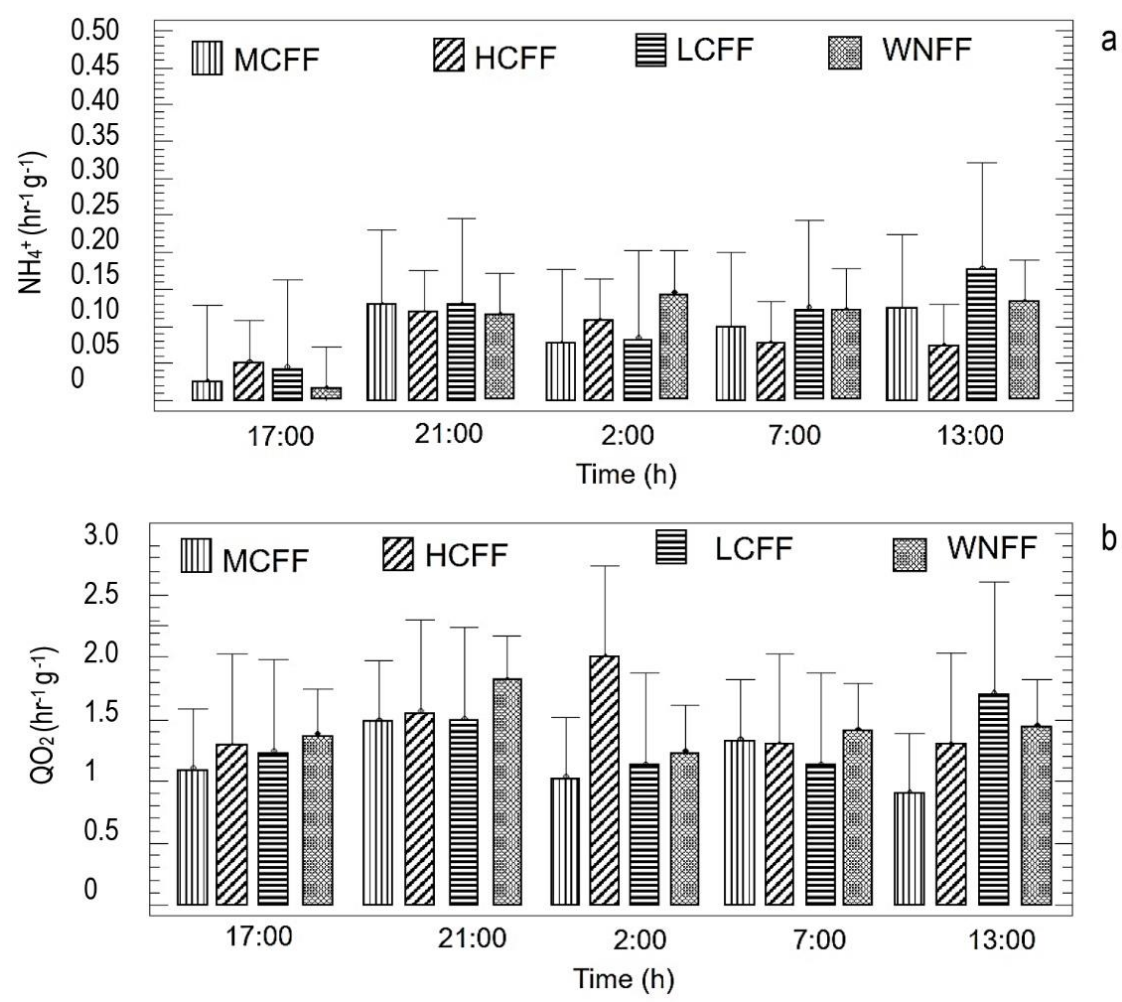

Figure 5. Results obtained from the respirometry by fish feed. a) $\mathrm{NH}_{4}{ }^{+}$excretion during $24 \mathrm{~h}$ by fishes in different treatments, b) dissolved oxygen consumption $\left(\mathrm{QO}_{2}\right)$ during $24 \mathrm{~h}$ by fishes in different treatments. LCFF: low-cost fish feed, MCFF: medium cost fish feed, HCFF: high-cost fish feed.
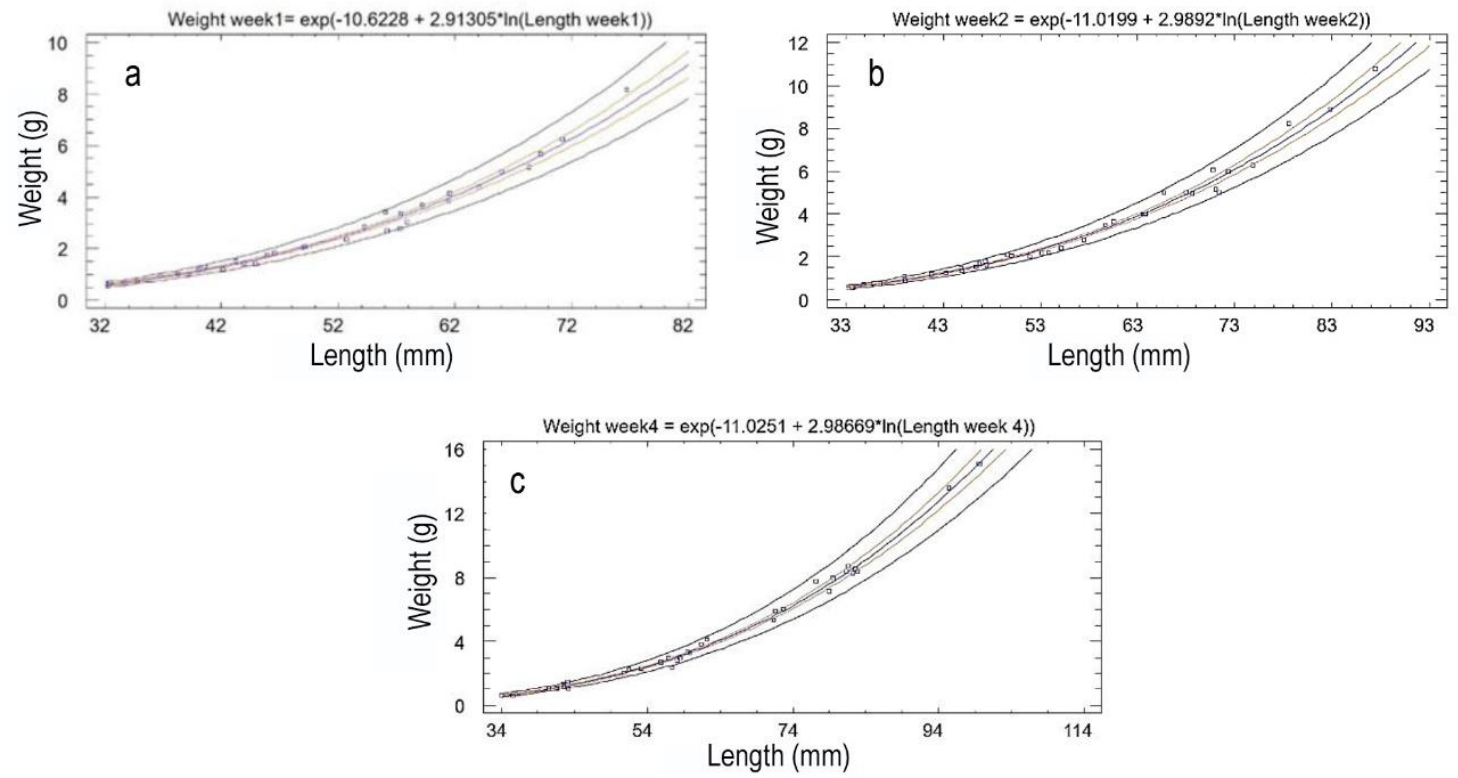

Figure 6. Relation length-weight presented in the treatment of medium-cost fish feed (MCFF). a) Week 1, b) week 2, c) week 4 .

the aquaculture wastewater is circulated to an additional treatment unit for purification, and cleaned water is recycled to be used for fish cultivation (Zou et al., 2016).
On the other hand the fish metabolic rate has a great importance because if organism stay a long time with low DO levels, it can potentially cause irreversible damage (Thorarinsdottir, 2015). Nevertheless, this rela- 

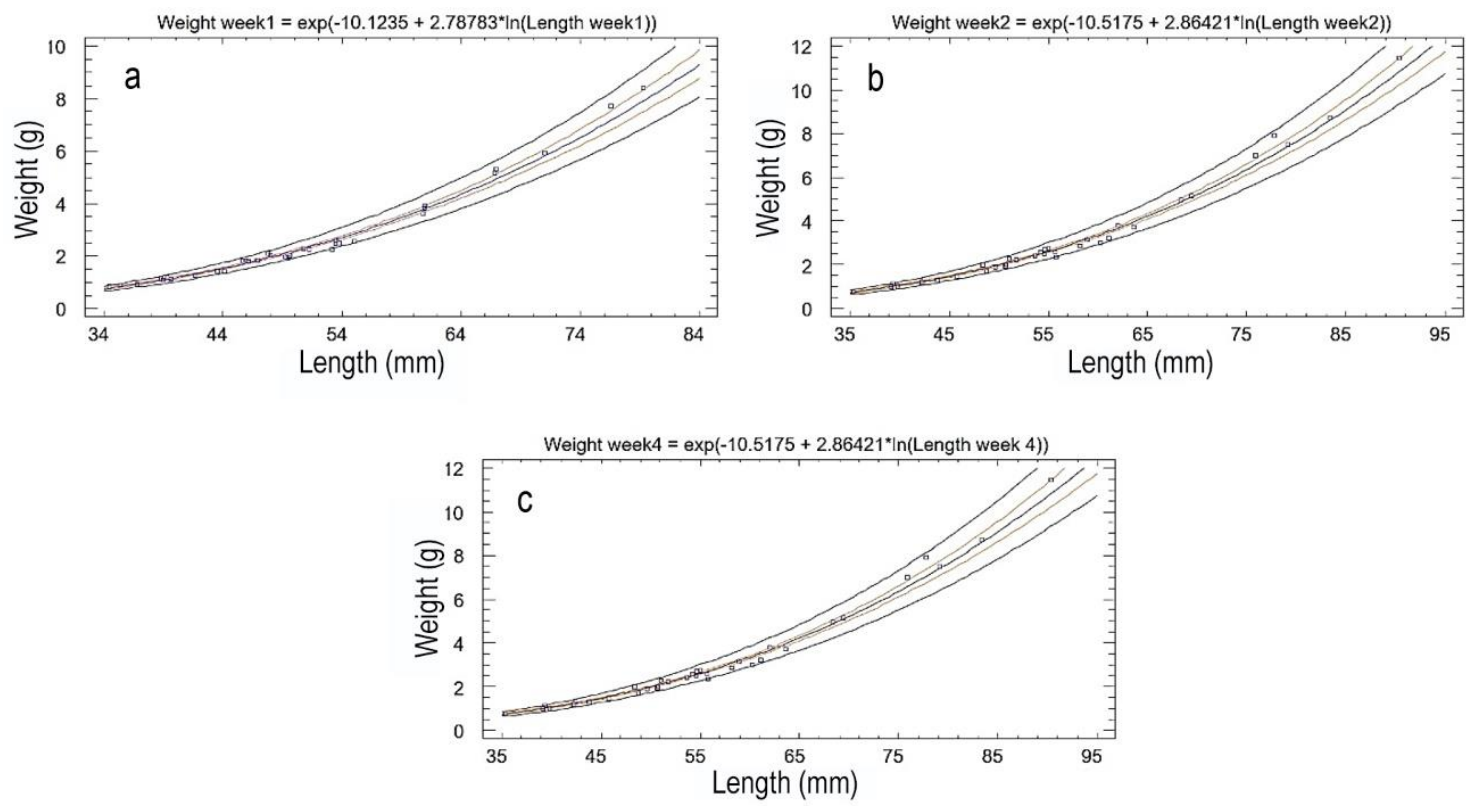

Figure 7. Relation length-weight presented in treatment of high-cost fish feed (HCFF). a) Week 1, b) week 2, c) week 4.
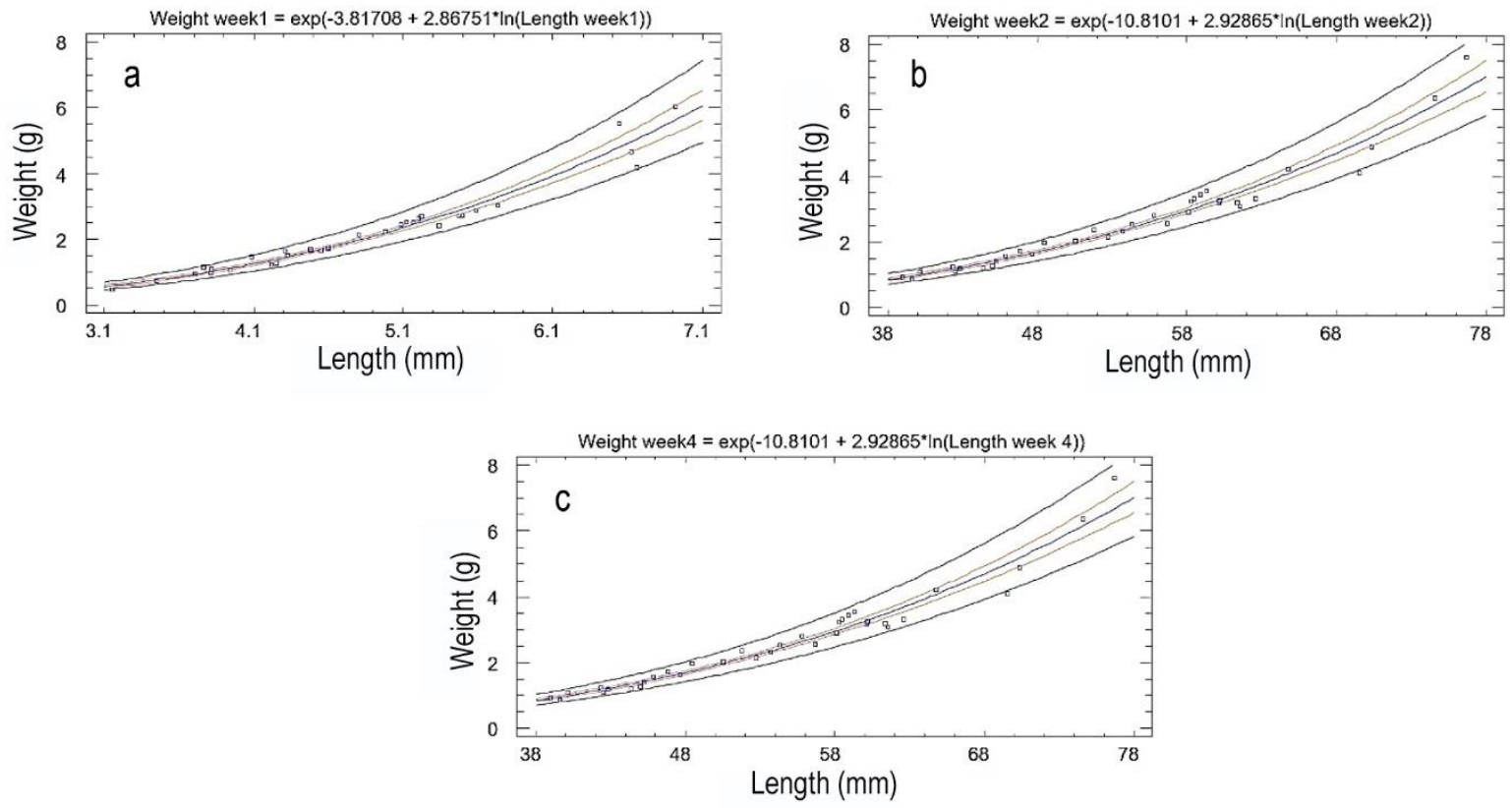

Figure 8. Relation length-weight presented in treatment of low-cost fish feed (LCFF). a) Week 1, b) week 2, c) week 4.

tes that fish had environmentally hypoxia, which induced a reduction in metabolic rate and suppression of ammonia production (Ip \& Chew, 2018). Maybe it could be necessary to make a digestibility study because of this kind of study rive due to how much of a given nutrient is digested by fish (Vilhelm et al., 2017). It can also be considered low metabolic waste because the waste production and dissolved oxygen consumption are similar (Mohammadi et al., 2019).
Where as the relation between length and weight has important implications in the first instance for fisheries science and then for the population dynamics (Torres et al., 2012). Additionally, the fish length can be an important parameter for the biologic process related to the absorption of nutrients and the correct metabolism (Sabaly et al., 2019). Nevertheless, in some cases, the food's protein is indigestible, and therefore the fish excretes feces as organic nitrogen (Lekang, 2013). 


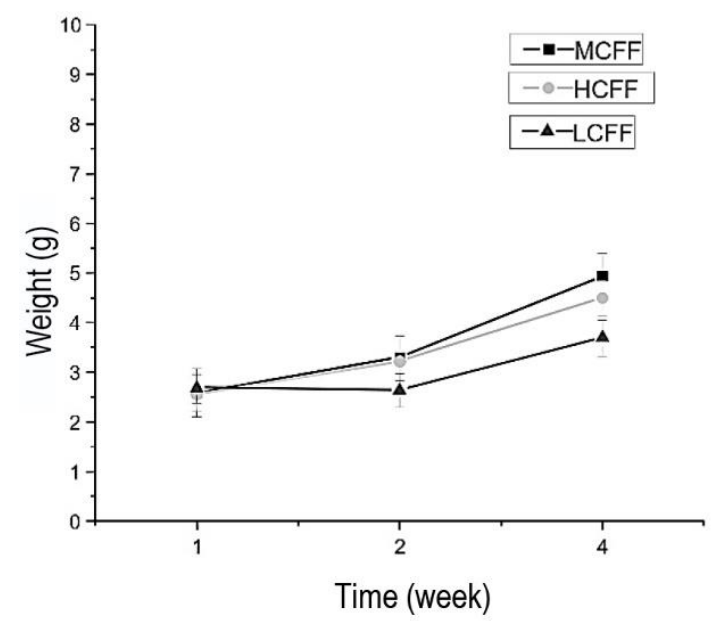

Figure 9. Growth obtained by treatments. LCFF: low-cost fish feed, MCFF: medium cost fish feed, HCFF: high-cost fish feed.

\section{CONCLUSIONS}

This study provided data related to three commercial fish feed with three different prices; these fish feed can be found in the research area. The fish feed that has better results on low excretion of nitrogen compound was MCFF and has good results associated with the length-weight relationship. This study fulfilled the aims set for it, and the data presented might constitute a valuable guideline for establishing new experiments related to the use of this fish feed.

\section{ACKNOWLEDGMENTS}

We want to thank all the study participants, especially to the Bioengineering Laboratories at Campus Amazcala of the Universidad Autónoma de Querétaro. CONACYT partially financed this work because of the scholarship for Ph.D. studies.

\section{REFERENCES}

Abdel-Tawwab, M., Monier, M.N., Hoseinifar, S.H. \& Faggio, C. 2019. Fish response to hypoxia stress: growth, physiological, and immunological biomarkers. Fish Physiology and Biochemistry, 45: $997-$ 1013, doi: 10.1007/s10695-019-00614-9

Boyd, C.E. 2013. Overview of aquaculture feeds: global impacts of ingredient use, feed and feeding practices in aquaculture. Elsevier, Amsterdam. doi: 10.1016/ B978-0-08-100506-4.00001-5

Dantas, G., Karina, M., Cabral, D.V. \& Gardner, I.A. 2017. Characterization of tilapia farming in net cages at a tropical reservoir in Brazil. Aquaculture Reports, 6: 43-48. doi: 10.1016/j.aqrep.2017.03.002
David, F.S. \& Proença, D.C. 2017. Nitrogen budget in integrated aquaculture systems with Nile tilapia and Amazon River prawn. Aquaculture International, 25: 1733-1746. doi: 10.1007/s10499-017-0145-y

Duodu, C.P., Adjei-boateng, D., Edziyie, R.E., Agbo, N.W., Owusu-boateng, G., Larsen, B.K. \& Skov, P.V. 2018. Processing techniques of selected oilseed byproducts of potential use in animal feed: effects on proximate nutrient composition, amino acid profile and antinutrients. Animal Nutrition, 4: 442-451. doi: 10.1016/j.aninu.2018.05.007

Estim, A., Saufie, S. \& Mustafa, S. 2018. Water quality remediation using aquaponics sub-systems as biological and mechanical filters in aquaculture. Journal of Water Process Engineering, 30: 100566. doi: 10.1016/j.jwpe. 2018.02.001

Food and Agriculture Organization (FAO). 2018. World fisheries and aquaculture. FAO, Rome.

Freitag, A.R., Thayer, L.R., Leonetti, C., Stapleton, H.M. \& Hamlin, H.J. 2015. Effects of elevated nitrate on endocrine function in Atlantic salmon, Salmo salar. Aquaculture, 436: 8-12. doi: 10.1016/j.aquaculture. 2014.10.041

Groenveld, T., Kohn, Y.Y., Gross, A. \& Lazarovitch, N. 2019. Optimization of nitrogen use efficiency by means of fertigation management in an integrated aquaculture-agriculture system. Journal of Cleaner Production, 212: 401-408. doi: 10.1016/j.jclepro.2018. 12.031

Hassaan, M.S., Soltan, M.A., Mohammady, E.Y., Elashry, M.A., El-Haroun, E.R. \& Davies, S.J. 2018. Growth and physiological responses of Nile tilapia, Oreochromis niloticus fed dietary fermented sunflower meal inoculated with Saccharomyces cerevisiae and Bacillus subtilis. Aquaculture, 495: 592-601. doi: 10.1016/j. aquaculture.2018.06.018

Hyacinth, J., Moniruzzaman, M. \& Park, Y. 2019. Evaluation of fish meal analogue as partial fish meal replacement in the diet of growing Japanese eel Anguilla japonica. Animal Feed Science and Technology, 247: 41-52. doi: 10.1016/j.anifeedsci.2018. 10.018

Ip, Y.K. \& Chew, S.F. 2018. Air-breathing and excretory nitrogen metabolism in fishes. Acta Histochemica, 120: 680-690. doi: 10.1016/j.acthis.2018.08.013

Isaza, D.F.G., Cramp, R.L. \& Franklin, C.E. 2018. Negative impacts of elevated nitrate on physiological performance are not exacerbated by low $\mathrm{pH}$. Aquatic Toxicology, 200: 217-225. doi: 10.1016/j.aquatox. 2018.05.004

Jisr, N., Younes, G., Sukhn, C. \& El-Dakdouki, M.H. 2018. Length-weight relationships and relative condition factor of fish inhabiting the marine area of the 
Eastern Mediterranean city, Tripoli-Lebanon. Egyptian Journal of Aquatic Research, 44: 299-305. doi: 10.1016/j.ejar.2018.11.004

Kim, K., Park, Y., Je, H., Seong, M., Damusaru, J.H., Kim, S., Jung, J. \& Bai, S.C. 2019. Tuna byproducts as a fish-meal in tilapia aquaculture. Ecotoxicology and Environmental Safety, 172: 364-372. doi: 10.1016/j.ecoenv.2019.01.107

Kokou, F. \& Fountoulaki, E. 2018. Aquaculture waste production associated with antinutrient presence in common fish feed plant ingredients. Aquaculture, 495: 295-310. doi: 10.1016/j.aquaculture.2018.06.003

Lekang, O. 2013. Aquaculture engineering. John Wiley \& Sons, New Jersey.

Lithgow, D., De la Lanza, G. \& Silva, R. 2017. Ecosystem-based management strategies to improve aquaculture in developing countries: a case study of marismas nacionales. Ecological Engineering, 130: 296-305. doi: 10.1016/j.ecoleng.2017.06.039

Ma, R., Liu, X., Meng, Y., Wu, J., Zhang, L. \& Han, B. 2019. Protein nutrition on sub-adult triploid rainbow trout: dietary requirement and effect on anti-oxidative capacity, protein digestion and absorption. Aquaculture, 507: 428-434. doi: 10.1016/j.aquaculture.2019. 03.069

Magnhagen, C., Backström, T., Nilsson, J. \& Brännäs, E. 2018. Oxygen consumption and swimming performance in Arctic charr with di ff erent pigmentation patterns. Applied Animal Behaviour Science, 202: 119-124. doi: 10.1016/j.applanim.2018.01.006

Mohammadi, M., Mahboobi-Soofiani, N., Farhadian, O. \& Malekpouri, P. 2019. Metabolic and NH 4 excretion rate of freshwater species, Chondrostoma regium in response to environmental stressors, different scenarios for temperature, and $\mathrm{pH}$. Science of the Total Environment, 648: 90-101. doi: 10.1016/j.scitotenv. 2018.08.131

Nguyen, L., Kubitza, F., Salem, S.M.R., Hanson, T.R. \& Allen-Davis, D. 2019. Comparison of organic and inorganic microminerals in all plant diets for Nile tilapia Oreochromis niloticus. Aquaculture, 498: 297304. doi: 10.1016/j.aquaculture.2018.08.034

Singh, R.P., Kolok, A.L. \& Bartelt-Hunt, S. 2019. Water conservation, recycling, and reuse: issues and challenges. Springer, Berlin.

Rodriguez, C., Galli, O., Olsson, D., Tellechea, J.S. \& Norbis, W. 2017. Length-weight relationships and condition factor of eight fish species inhabiting the Rocha Lagoon, Uruguay. Brazilian Journal of Oceanography, 65: 97-100.

Sabaly, B., Fall, M., Kantoussan, J. \& Ngom, F. 2019. Fish-length based indicators for improved management of the sardinella fisheries in Senegal. Regional Studies in Marine Science, 31: 100801. doi: 10.1016/j. rsma.2019.100801
Soto-Zarazúa, G.M., Rico-García, E., Ocampo, R., Guevara-González, R.G. \& Herrera-Ruiz, G. 2010. Fuzzy-logic-based feeder system for intensive tilapia production (Oreochromis niloticus). Aquaculture International, 18(3): 379-391.

Steffensen, J.F. 1989. Some errors in respirometry of aquatic breathers: how to avoid and correct for them. Fish Physiology and Biochemistry, 6: 49-59.

Svobodova, Z., Machova, J., Kroupova, H.K. \& Velisek, J. 2017. Water quality - disease relationship on commercial fish farms, fish diseases: prevention and control strategies. Elsevier, Amsterdam. doi: 10.1016/ B978-0-12-804564-0.00007-7

Thi, N., Ha, K., Thi, D., Huong, T., Thanh, N., Bayley, M. $\&$ Bo, F. 2019. Impact and tissue metabolism of nitrite at two acclimation temperatures in striped catfish (Pangasianodon hypophthalmus). Aquatic Toxicology, 212: 154-161. doi: 10.1016/j.aquatox.2019.05.008

Thorarinsdottir, R.I. 2015. Aquaponics guidelines. Lifelong Learning Programme, Haskolaprent, Reykjavik.

Timmons, M.B., Ebeling, J.M., Wheaton, F.W., Summerfelt, S.T. \& Vinci, B.J. 2002. Recirculating aquaculture systems. Cayuga Aqua Ventures, New York.

Torres, M.A., Ramos, F. \& Sobrino, I. 2012. Lengthweight relationships of 76 fish species from the Gulf of Cadiz (SW Spain). Fisheries Research, 127-128: 171-175. doi: 10.1016/j.fishres.2012.02.001

Valenti, W.C., Kimpara, J.M., Preto, B. \& MoraesValenti, P. 2018. Indicators of sustainability to assess aquaculture systems. Ecological Indicators, 88: 402413. doi: 10.1016/j.ecolind.2017.12.068

Vilhelm-Skow, P., Prah-Doudu, C. \& Adjei-Boateng, D. 2017. The influence of ration size on energetics and nitrogen retention in tilapia (Oreochromis niloticus). Aquaculture, 473: 121-127. doi: 10.1016/j.aquaculture.2017.02.007

Wang, J., Liang, D., Yang, Q., Tan, B., Dong, X., Chi, S., Liu, H. \& Zhang, S. 2019. The effect of partial replacement of fish meal by soy protein concentrate on growth performance, immune responses, gut morphology and intestinal inflammation for juvenile hybrid grouper (Epinephelus fuscoguttatus + + $\times$ Epinephelus lanceolatus ${ }^{\lambda}$ ). Fish and Shellfish Immunology, 98: 619-631. doi: 10.1016/j.fsi.2019.10.025

Xie, L., Chen, S., Yao, C., Li, D., Li, L. \& Tang, R. 2019. Nitrite induces endoplasmic reticulum stress and associates apoptosis of liver cells in grass carp (Ctenopharyngodon idella). Aquaculture, 507: 275281. doi: 10.1016/j.aquaculture.2019.04.016

Yang, X., Song, X., Peng, L., Hallerman, E. \& Huang, Z. 2019. Effects of nitrate on aquaculture production, 
blood, and histological markers and liver transcriptome of Oplegnathus punctatus. Aquaculture, 501: 387-396. doi: 10.1016/j.aquaculture.2018.11.048

Yun, L., Yu, Z., Li, Y., Luo, P., Jiang, X., Tian, Y. \& Ding, X. 2019. Ammonia nitrogen and nitrite removal by a heterotrophic Sphingomonas sp. Strain LPN080 and its potential application in aquaculture. Aquaculture, 500: 477-484. doi: 10.1016/j.aquaculture.2018.10.054

Zhou, C., Lin, K., Xu, D., Chen, L., Guo, Q. \& Sun, C. 2018. Near infrared computer vision and neuro-fuzzy model-based feeding decision system for fish in aquaculture. Computers and Electronics in Agriculture, 146: 114-124. doi: 10.1016/j.compag.2018. 02.006

Received: 20 April 2020; Accepted: 28 July 2020
Zhou, C., Zhang, B., Lin, K., Xu, D., Chen, C., Yang, X. \& Sun, C. 2017. Near-infrared imaging to quantify the feeding behavior of fish in aquaculture. Computers and Electronics in Agriculture, 135: 233-241. doi: 10.1016/j.compag.2017.02.013

Zou, Y., Hu, Z., Zhang, J., Xie, H., Liang, S. \& Wang, J. 2016. Attempts to improve nitrogen utilization efficiency of aquaponics through nitrifies addition and filler gradation. Environmental Science and Pollution Research International, 23(7): 6671-6679. doi: 10.1007/s11356-015-5898-0 